\title{
Metadisciplina aplicada em Projeto de Produto, a formação de um coletivo de Design.
}

\author{
Metadiscipline applied in Product Design, the formation of a Design collective. \\ Anna Lúcia dos Santos Vieira e Silva, Adson Pinheiro Queiroz Viana, Marina de Sousa \\ Santos, Ana Beatriz Teixeira Marciano, Bruno Ribeiro do Nascimento \& Alessandra do \\ Nascimento Pereira.
}

\begin{abstract}
metadisciplina; metadesign; coletivo de design.
Este artigo aborda o estudo de caso de uma experiência didática relativa à última disciplina de Projeto do ciclo profissionalizante do curso de Design da Universidade Federal do Ceará, que abrange o design de sistemas complexos e dinâmicos. Com as bases em Metaprojeto (Moraes, 2010), Metadesign (Vassão, 2010) e Complexidade (Cardoso, 2012) a disciplina é proposta na abordagem da Metadisciplina, na qual todos os participantes são co-responsáveis por construí-la durante sua realização. No caso desta disciplina específica, há uma coerência interna, sendo a própria Metadisciplina um sistema complexo e dinâmico a ser solucionado. O Design de Informação aparece em diferentes níveis neste processo: na necessidade de organização de informações complexas; na sistematização do planejamento progressivo da disciplina e dos projetos; na visibilidade e entendimento dos sistemas identificados e resultantes; e no projeto realizado. $O$ estudo de caso se refere a um grupo de sete estudantes que surge com interesse num assunto em voga: a possibilidade da candidatura de Fortaleza ao título de Cidade Criativa da UNESCO no quesito Design. Identificam no processo três subsistemas relativos aos aspectos onde a prática do design opera: design e sociedade; design e mercado; design e ensino. No lugar de apresentar um projeto, o grupo se apresenta como um coletivo, uma solução aberta, dinâmica e catalisadora que imerge e atua no próprio sistema. Como resultado, o coletivo propõe uma plataforma física e interativa, com uma narrativa visual e espacial sobre design a ser implantada como marco visual em pontos estratégicos da cidade.
\end{abstract}

metadiscipline; metadesign; collective of design.

This article approaches the case study of a didactic experience related to the last discipline of Design of the vocational cycle of the Federal University of Ceará, which covers the design of complex and dynamic systems. Based in Metaproject (Moraes, 2010), Metadesign (Vassão, 2010) and Complexity (Cardoso, 2012) the discipline is proposed in the approach of Metadisciplina, which all the participants are coresponsible for constructing it during its accomplishment, in the case of this specific discipline, with an internal coherence being itself a complex and dynamic system to be solved. Information Design appears at different levels in this process: the need to organize complex information; in the systematization of the progressive planning of the discipline and the projects; in the visibility and understanding of the resulting systems and in the project carried out. The case study refers to a seven students group who came up with an interest in a topic in vogue: the possibility of Fortaleza's run for the title of Creative City of UNESCO in the Design category. They identify in the process three subsystems related to aspects where the practice of design operates: design and society; design and market; design and teaching. Instead of presenting a project, the group presents itself as a collective: an open, dynamic and catalytic solution that immerses and acts in the system itself. As a result, the collective proposes a physical and interactive platform, with a visual and spatial narrative about design to be implanted as a visual landmark in strategic points of the city.

\section{Introdução}

O artigo apresenta a formação de um coletivo de Design durante uma disciplina de projeto de produto no segundo semestre de 2018. Inicialmente, a disciplina é observada na estrutura do

\author{
Anais do 9 CIDI e 9 CONGIC \\ Luciane Maria Fadel, Carla Spinillo, Anderson Horta, \\ Cristina Portugal (orgs.) \\ Sociedade Brasileira de Design da Informação - SBDI \\ Belo Horizonte | Brasil | 2019 \\ ISBN 978-85-212-1728-2
}

Proceedings of the 9th CIDI and 9th CONGIC

Luciane Maria Fadel, Carla Spinillo, Anderson Horta, Cristina Portugal (orgs.)

Sociedade Brasileira de Design da Informação - SBDI

Belo Horizonte | Brazil | 2019

ISBN 978-85-212-1728-2 
curso de Design, em seus conteúdos e em relação a abordagem pedagógica sobre a qual se desenvolve e fundamenta: a Metadisciplina.

O design de informação é apropriado desde o início como meio de entendimento dos diversos interesses dos estudantes e na formação de grupos que propõem diferentes projetos a partir de um metaprojeto comum.

Um dos grupos que se formou por similaridade de interesses é analisado aqui como um estudo de caso em seu processo de formação, que abrange questionamentos sobre design de um ponto de vista sistêmico, tais como suas relações com a universidade (cursos de Design), com as comunidades (que consomem artefatos de Design) e com o mercado (escritórios e serviços de Design) inseridos na cidade de Fortaleza.

No grupo, outras formas de utilização do design da informação são aplicadas, como na organização e visualização da complexidade do tema; como instrumento de compreensão dos sistemas que se formam durante a pesquisa, na análise das conexões fragilizadas entre os elementos identificados; no desenvolvimento de propostas; na elaboração do projeto; e em uma produção resultante de todo processo, uma vez que o design de informação é fundamental para proposição de novas conexões sistêmicas e ao entendimento das existentes.

\section{O curso}

O curso de Design da Universidade Federal do Ceará é estruturado em três ciclos: o primeiro ano, de fundamentação, nos dois anos seguintes o ciclo profissionalizante e o último ano de conclusão, com conteúdos de complexidade gradativamente crescente a cada semestre. $O$ último ano é o de conclusão.

\section{Metadisciplina em Projeto de Produto 4 (PP4)}

A disciplina de Projeto de Produto 4, cujo processo será analisado neste artigo, é a última do ciclo profissionalizante e tem como objetivo explorar, por meio do design, sistemas complexos e dinâmicos na atualidade. Desde 2015, PP4 se desenvolve pela abordagem pedagógica da Metadisciplina, proposição aplicada a uma disciplina que se constrói enquanto é ministrada. Além de cumprir com os objetivos da ementa, os conteúdos, planejamentos e critérios de avaliação são definidos ao longo do processo pedagógico por professores, monitores e estudantes, de forma criativa e participativa.

\section{Conceituação teórica}

Os conceitos de sistemas, complexidade e dinâmica que fundamentam PP4, são abordados como conteúdos combinados ao Metaprojeto (Moraes, 2010), como método de construção dos parâmetros iniciais; Metadesign (Vassão, 2010), como uma forma de compreender, abarcar e modificar o contexto onde o design é proposto; e a Metadisciplina, como abordagem e metodologia ativa.

\section{Sistemas e Complexidade}

A disciplina é aberta, abrangente, sem um tema definido a priori e contempla desdobramentos e especificidades, onde a compreensão das relações entre as partes é fundamental para o entendimento do todo. Então, o conceito da Teoria Geral dos Sistemas (TGS) favorece o próprio entendimento da disciplina, como um conjunto de elementos que possuem um conjunto de relações entre si e que fazem emergir uma série de propriedades (Vieira, 2008).

O segundo conceito que fundamenta a disciplina e que lhe dá coerência é o da complexidade, bastante associada à prática do design contemporâneo.

"(...) aquilo que não pode ser disposto, apresentado, compreendido como algo simples, que não pode ser decomposto em pedaços menores e, portanto, mais simples, que não pode ser "reduzido". Ou

seja, algo que é, por natureza, pelas suas próprias características, "irredutível"." (Vassão, 2010, p.13).

Enquanto a TGS aborda a complexidade como um parâmetro sistêmico livre, que acompanha a evolução do sistema, Cardoso a define como "um sistema composto por muitos 
elementos, camadas e estruturas cujas inter-relações condicionam e redefinem continuamente o funcionamento do todo" (Cardoso, 2012, p.25) e em seguida traz a metáfora de uma metrópole. Os conceitos de sistema e de complexidade combinados, pressupõe o terceiro parâmetro da disciplina, a dinâmica das transformações inerentes à realidade atual. 'No mundo complexo em que vivemos, as melhores soluções costumam vir do trabalho em equipes e em redes.' (Cardoso, 2012, p. 22-23).

Com esta compreensão, o conteúdo programático não pode ser reduzido, sob a pena de perder complexidade ou reduzir o sistema. Tampouco seria coerente uma proposta de projeto definida ou dentro de uma estrutura rígida, incapaz de absorver em sua dinâmica diversos conteúdos.

\section{Metaprojeto}

Em sua origem o conceito de metaprojeto (Moraes, 2010) considera o projeto por meio de uma análise das demandas e da situação na qual o projeto será proposto, sob os pontos de vista das condições mercadológicas, sistêmicas, ambientais, socioculturais, formais, ergonômicas, tecnológica em termos produtivos e materiais. Justamente por sua abrangência, objetiva a construção de um entendimento conceitual, "um modelo dinâmico no qual se fazem verificações contínuas", como uma referência de parâmetros que podem ser verificados em todas as fases de desenvolvimento do projeto, "um modelo flexível em que as decisões tendem a ser reversíveis." (Moraes, 2010, p. 31)

"Nesse sentido, a ação de conhecimento e de análise prévia da realidade existente (cenário atual) ou prospectada (cenário futuro) faz plenamente parte do processo de design. O profissional, nesse caso, deve ser capaz de traçar os limites, analisar e, sobretudo, realizar uma síntese compreensível de cada etapa projetual já por ele superada." (Moraes, 2010, p. 21).

Em termos operacionais o conceito de metaprojeto se aplica como estratégia didática em PP4, na construção dos parâmetros iniciais que antecedem o projeto, ao contemplar a análise dos contextos, fluxos e novas relações possíveis dentro dos sistemas observados. Realizado em situações mais específicas, quando os grupos ou indivíduos já definiram seus interesses de projeto, o metaprojeto também indica as intenções dos estudantes em relação aos sistemas (sobre o qual se projeta e a ser projetado).

\section{Metadesign}

O metadesign (Vassão, 2012) propõe um duplo sentido ao design na dinâmica de situações complexas: contempla o ato de projetar o contexto onde o projeto está inserido, operando transformações do meio, através do design. Os resultados são mais fundamentados em processos que em objetos propriamente ditos, principalmente por estar pautado no constante movimento dos contextos onde opera. O metadesign é uma forma de transformar e atuar em complexidades dinâmicas.

“(...) parte do Metadesign é reconhecer como a realidade, enquanto representação de um mundo que provavelmente estará além de nossa compreensão absoluta, é um objeto de trabalho, uma obra individual e/ou coletiva, e que, quando ela torna-se coletiva, é ainda outro processo de construção de uma realidade comungada. (Vassão, 2010, p.16)"

O designer que utiliza o metadesign tem como função acelerar transformações sociais com proposições colaborativas e co-criativas, induzindo agentes criativos neste processo, e a criatividade aqui está intimamente ligada ao saber usar dos aspectos do contexto como ferramenta para transformá-lo. É um constante olhar sobre si mesmo ao atuar em seu meio e saber o que se quer mudar no todo, com ações no presente.

O metadesign parte do princípio de que a complexidade pode ser conhecida e manipulada, por ferramentas apropriadas, capazes de facilitar a compreensão da complexidade por níveis, camadas, categorias e outros atributos dependendo do tipo de sistema. Isso permite o desmembramento do sistema complexo identificado por temas, para análise das partes, sem perda de complexidade e eleva o projeto para um nível de prospecção intencionalmente ligado às suas relações com o contexto de origem. Essa construção abraça o Design da Informação por completo ao aplicar dispositivos visuais e simbólicos na visualização e elaboração das diferentes escalas de complexidade. 'O interessante, e talvez surpreendente, é que o universo 
tende a se organizar de um modo que haja "entidades compreensíveis" em qualquer escala de complexidade que o observamos, que podem ser entendidas em seu próprio nível.' (Vassão, 2010, p.27).

A Metadisciplina incorpora esse conceito ao propor o estudo de diferentes escalas de complexidade desde o início. Em uma escala menor, na composição da disciplina por todos participantes. Num nível mais complexo, nas proposições de design resultantes, que compreendem, representam e atuam em sistemas complexos e dinâmicos, em soluções possíveis, escaláveis e participativas.

\section{Design de informação}

A produção de projetos complexos envolve processos que se refletem em modos de organização e na relação entre os atores envolvidos. A possibilidade de atrito ou divergências indica uma necessidade de organização harmônica.

Para que a informação não seja considerada apenas um conjunto de dados, sem estrutura ou contexto (Baer, 2009), o design da informação atua. Essa categoria do design facilita a recepção e a interpretação da mensagem no meio que é transmitida. Seleção, ordenamento, hierarquização, conexões e distinções da linguagem visual influenciam na produção de sentido. O designer da informação, além de tradutor, estrutura os dados, planeja e verifica a eficiência na transmissão das informações, agindo nesse sentido, também como coautor (Bonsiepe, 2011).

O design de informação aparece em diferentes níveis em PP4: na organização de informações complexas (figuras 1, 2, 3, 6, 7, 8 e 9); na sistematização do planejamento progressivo da disciplina e dos projetos (figura 2 e 3 ); nos resultados das pesquisas históricas (figura 4 e 5); na visibilidade e entendimento do sistema resultante com movimentos e conexões resultantes (figura 6, 7 e 8); na realização do projeto (figura 9,10,11,12 e 13).

\section{Metadisciplina}

Metadisciplina é uma abordagem pedagógica que se fundamenta em três áreas do conhecimento: o Design; a Didática e a Semiótica peirceana. A interação dos fundamentos determina três princípios: querer juntos, fazer juntos e pensar juntos. Em termos de aplicação, os princípios são traduzidos em três módulos na construção compartilhada de conteúdos, experiências e conhecimentos.

Em PP4 o método foi aplicado da seguinte maneira: módulo 1 "Querer juntos" - construção compartilhada de conteúdos, pesquisa de interesses, perguntas de interesses, conexão de interesses comuns, metaprojeto; módulo 2 "Fazer juntos" - definição do tema dos grupos ou indivíduos, perguntas de projeto, pesquisa do tema, análise de similares, definição do sistema geral, metaprojeto dos temas específicos dos grupos ou indivíduos; módulo 3 "Pensar juntos" Visualização do novo sistema com as proposições ao sistema existente, indicativo e apresentação das soluções propostas (variável de acordo com cada projeto). 
Silva, A. L. S. V., Viana, A. P. Q., Nascimento, B. R., Santos, M. S., Marciano, A. B. T. \& Pereira, A. N. / Metadisciplina aplicada em Projeto de Produto, a formação de um coletivo de Design.

Figura 1: Infográfico da definição dos módulos da metadisciplina a partir dos fundamentos. Fonte: Grupo de formação do coletivo.

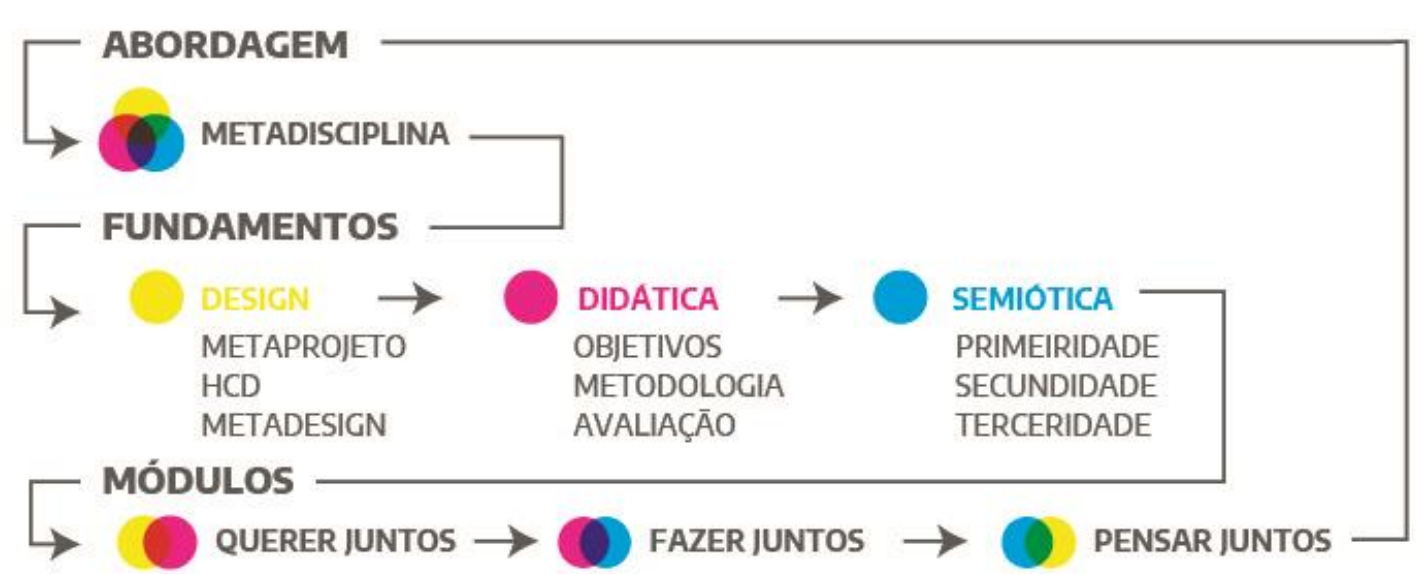

Em uma Metadisciplina aplicada, estudantes e professores definem os conteúdos de interesse relativos à disciplina; o planejamento do processo de aprendizagem; plataformas de comunicação e partilhas; temas; parâmetros e formas de desenvolvimento; critérios e modos de avaliação.

"Existem desafios na aplicação de abordagens disruptivas no contexto dos métodos tradicionais de ensino e aprendizagem e de projeto em design. No entanto, a intersecção dessas áreas dá voz aos diversos pontos de vistas que podem ser agregados e combinados na produção de uma miríade de soluções relevantes e inovadoras no ensino e no design." (Silva, et. al. 2018)

Essa proposição abre espaço de fala entre pessoas de diferentes origens, expressões, interesses e pressupostos, com isso promove uma comunidade de aprendizado em que os alunos se vêem mutuamente responsáveis pelo desenvolvimento da comunidade e do aprendizado, a partir da escuta reconhecida e valorizada. (Hooks, 2017)

Em PP4 a Metadisciplina ganha uma coerência interna uma vez que os conceitos de design que as fundamentam coincidem.

\section{Primeira fase da Metadisciplina em PP4 2018}

Em 2018, PP4 começa com o consenso da turma em ser Metadisciplina. Em seguida o planejamento do "sistema PP4" (Figura 2), antes das definições dos projetos, com os critérios para definição de plataformas de partilha (Figura 3) e os conteúdos de interesse. 
Silva, A. L. S. V., Viana, A. P. Q., Nascimento, B. R., Santos, M. S., Marciano, A. B. T. \& Pereira, A. N. / Metadisciplina aplicada em Projeto de Produto, a formação de um coletivo de Design.

Figura 2: Infográfico da criação das diretrizes projetuais direcionados pelo metaprojeto.

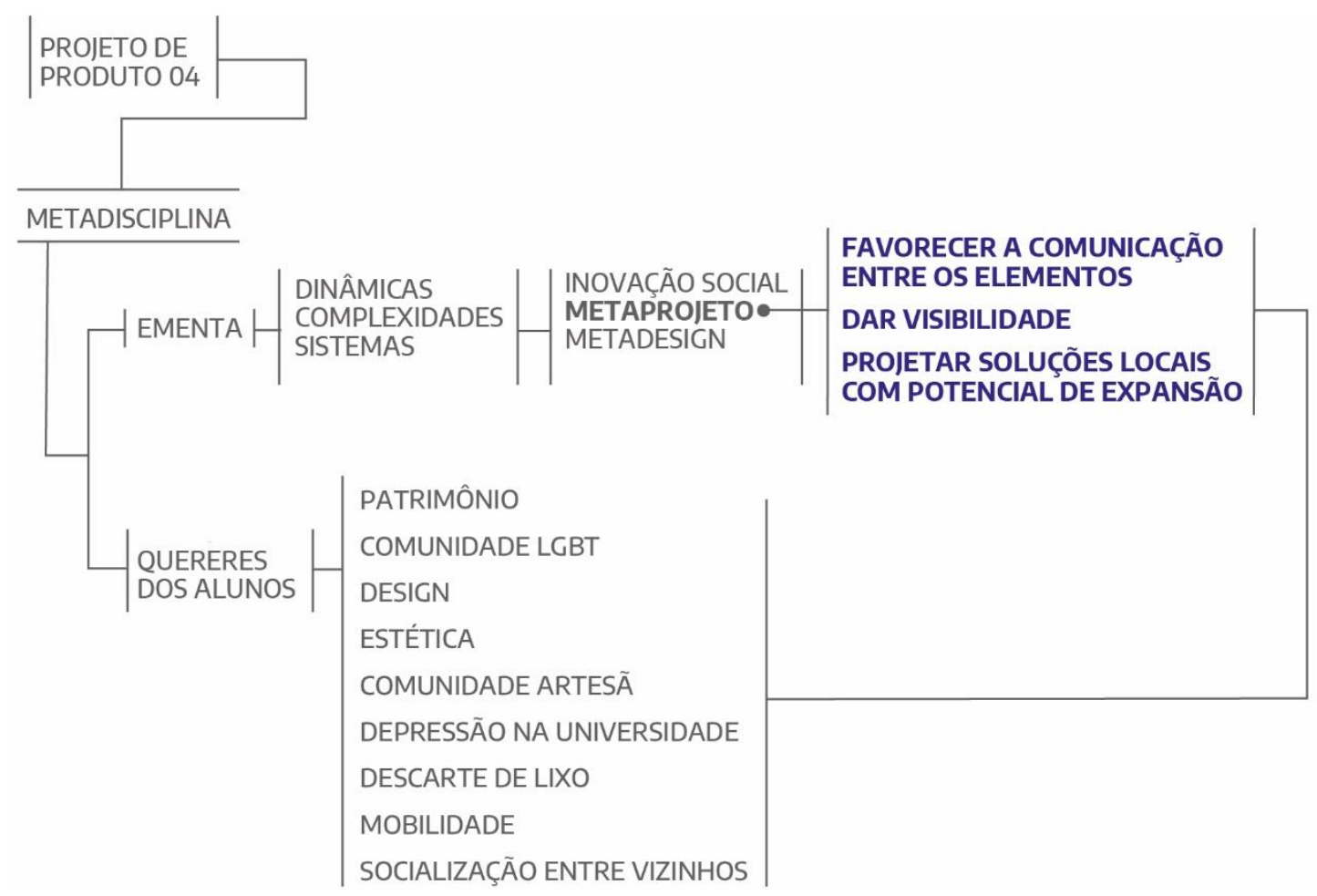

Figura 3: Diretrizes para plataforma de partilha processual de informações, estabelecidas por estudantes e professores. Fonte: Grupo de formação do coletivo.

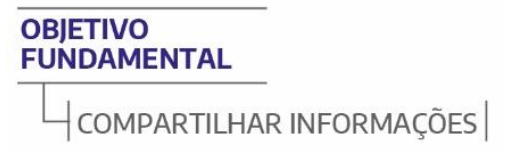

\section{Estudo de caso Design em Fortaleza}

Durante a etapa de aprofundamento estava em discussão a pré-candidatura de Fortaleza como Cidade Criativa da Organização das Nações Unidas para a Educação, a Ciência e a Cultura (UNESCO) no quesito Design. Diante disso, os alunos, a partir de sua posição de estudantes de Design e futuros profissionais, questionaram-se: Qual é a produção de Design no Ceará? Há um Design com identidade local? Quem está produzindo? Como tem sido feito? Para que e para quem tem servido? Como a sociedade acessa o Design? O design feito na universidade é visto pelo mercado de trabalho e vice-versa? A formação do grupo com interesse comum foi considerada a primeira complexidade a ser organizada e regida. 
Silva, A. L. S. V., Viana, A. P. Q., Nascimento, B. R., Santos, M. S., Marciano, A. B. T. \& Pereira, A. N. / Metadisciplina aplicada em Projeto de Produto, a formação de um coletivo de Design.

\section{Metodologia projetual}

Para compreender os elementos quantitativos e qualitativos do sistema "Design em Fortaleza" foi necessário acolher o anseio de todos os membros do grupo e torná-los demandas de projeto, utilizando-se da sistematização das informações por critério de semelhança e correlação para servir de suporte legível a todos e permitir a continuidade nas discussões sobre o tema já identificado como complexo, denso e multifacetado.

Considerando a não-linearidade das perguntas e respostas do grupo, foram feitas pesquisas bibliográficas sobre a história do ensino de Design na cidade (Figura 4) com comparações no âmbito nacional-estadual. Em seguida uma investigação e análise dos produtores, produtos e tipos de design em escritórios brasileiros (Figura 5). Essas informações sistematizadas visualmente foram determinantes para embasar a percepção atual do mercado e, com diversas análises, direcionar o recorte e a estrutura a ser seguida.

Figura 4: Linha do tempo relativa ao histórico do ensino do Design no Ceará. Fonte: Grupo de formação do coletivo.

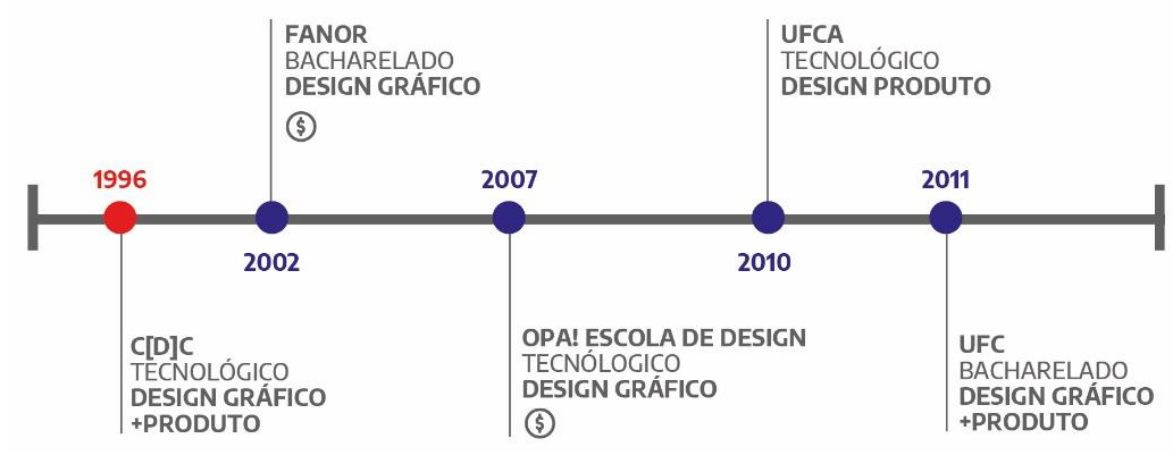

Figura 5: Áreas de atuação dos escritórios de design no Brasil. Fonte: Grupo de formação do coletivo. - Adaptado do Diagnóstico do Design Brasileiro. (Brasil, 2014)

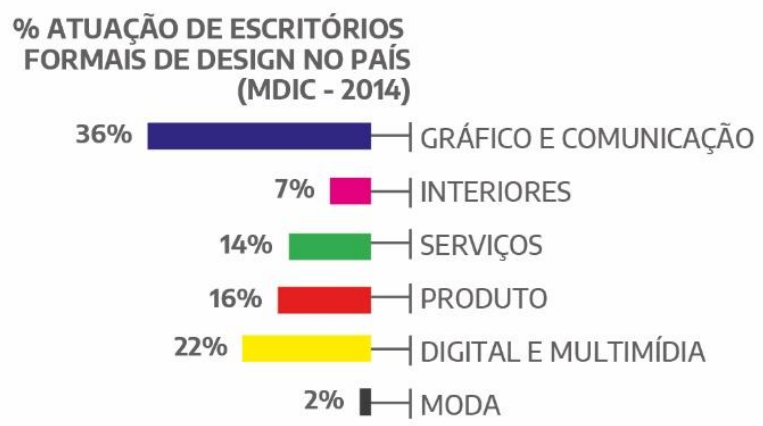

Dada a complexidade optou-se por dois recortes para os parâmetros do projeto: o foco de pesquisa na capital do Ceará, Fortaleza, e em duas áreas específicas do Design, o gráfico e o produto, devido aos tipos de escritórios atuantes (no Brasil e no contexto local) e da pesquisa histórica realizada. 
Silva, A. L. S. V., Viana, A. P. Q., Nascimento, B. R., Santos, M. S., Marciano, A. B. T. \& Pereira, A. N. / Metadisciplina aplicada em Projeto de Produto, a formação de um coletivo de Design.

\section{O Sistema}

O sistema Design em Fortaleza representado pela Figura 6, apresenta três subsistemas: dois produtores: ensino e mercado, e um receptor: sociedade. Os elementos percorrem os subsistemas de acordo com o ofício, redes de design, atuações e conexões.

Nos subsistemas ensino e mercado, os agentes se apresentam como a rede de produção de conhecimento e de artefatos de design. No subsistema sociedade os receptores de design são classificados de acordo com a maneira que interagem com o design.

O design de informação possibilitou uma visualização única e explicativa do sistema os autores, com a identificação de quatro tipos de conexões: frágeis, ausentes, invisíveis e possíveis.

Figura 6: Conexão dos três subsistemas de design gráfico e de produto em Fortaleza. Fonte: Grupo de formação do coletivo.

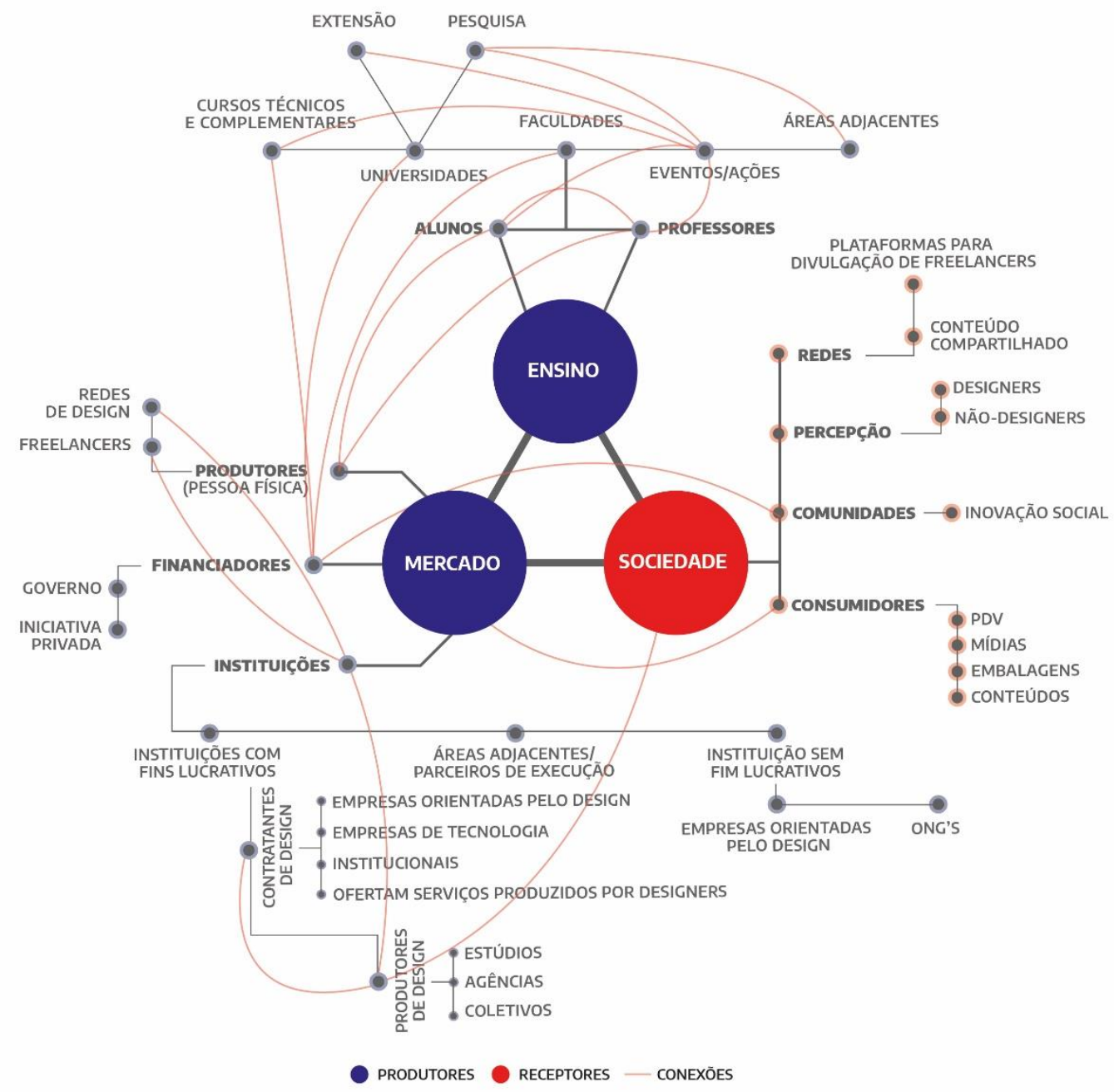

Outro estudo do grupo traduziu os cinco quesitos de Lynch, (1960) - áreas, vias, limites, pontos nodais e marcos visuais - para adaptar o sistema a uma nova perspectiva, ao realocálos em um campo abstrato relativo ao sistema em questão (Figura 7).

As áreas se tornaram os três subsistemas e alguns de seus elementos. As vias correspondem a ligações internas de elementos do subsistemas. Os limites correspondem a campos de conhecimento e produções que, mesmo no diálogo com o design, possuem especificidades próprias. Considerando o campo abstrato, esses limites se extrapolam recorrentemente. Pontos nodais se traduzem em momentos, ações ou lugares estratégicos de 
Silva, A. L. S. V., Viana, A. P. Q., Nascimento, B. R., Santos, M. S., Marciano, A. B. T. \& Pereira, A. N. / Metadisciplina aplicada em Projeto de Produto, a formação de um coletivo de Design.

encontro dos subsistemas (ensino, mercado e sociedade), enquanto os marcos visuais se tornam acontecimentos que favorecem que a sociedade reconheça o design.

Figura 7: Paralelo da imagem da cidade proposto por Lynch (1960) e o sistema de design em Fortaleza. Fonte: Grupo de formação do coletivo.

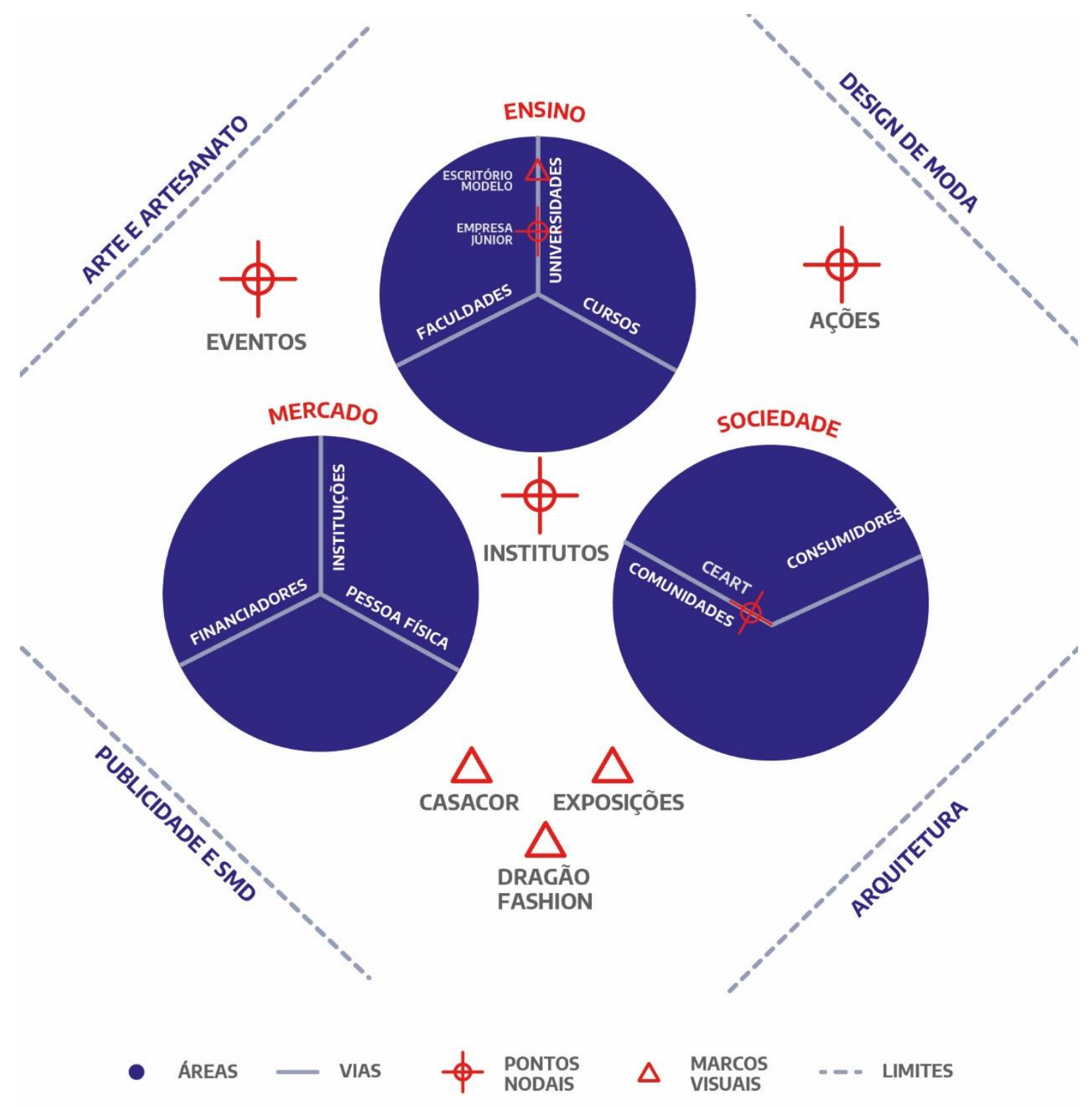

\section{Análise dos subsistemas}

Os subsistemas foram analisados separadamente e, em seguida, identificados os aspectos concernentes a suas conexões.

\section{Design e Sociedade}

O subsistema sociedade buscou entender qual é a imagem que o público geral tem sobre design. No início intuito de obter dados objetivos, foi elaborado um questionário qualitativo (cinco palavras que definem design e, brevemente, o que é design para você?). Mesmo sem ser uma pesquisa científica, as respostas expõem que o design ainda é desconhecido para a maioria das pessoas que se dispuseram a responder. Assim, o subsistema foi classificado em quatro aspectos de acordo com a forma ou o meio que dialogam com o design: percepção - 
ponto de vista dado por designers e não-designers; comunidade - grupos que interagem no espaço público através do design social, com projetos e ações de impacto positivo na sociedade; consumidores - da indústria cultural, de produtos industrializados, consumo direto da produção capitalista; redes de design - plataformas virtuais de desenvolvimento e partilha de conteúdos especializados em design.

\section{Design e Mercado}

No subsistema mercado, a pesquisa é direcionada à classe representativa da área: empresas com fins lucrativos produtoras de design. A partir do levantamento (Pereira, 2017) com oito estúdios de design de produto e sete de design gráfico atuantes em Fortaleza, as informações indicam a ausência de espaços de debate sobre design e a possibilidade de novas propostas de design no mercado.

\section{Design e Ensino}

O subsistema ensino compreende todos os elementos envolvidos na transmissão, produção e compartilhamento de conhecimento em Design em Fortaleza. O levantamento contabilizou sete instituições que ofertam o ensino de Design, três instituições de ensino técnico e outras três de ensino superior, sendo duas particulares e uma pública. As informações foram obtidas por meio de materiais disponibilizados publicamente por cada instituição e por formulário enviado à coordenação de todos os cursos com questionamentos sobre sua fundação, estrutura de funcionamento, quadro de docentes, taxas de admissão e evasão de discentes, identificação de iniciativas acerca da introdução ao mercado de trabalho e desenvolvimento de projetos de extensão e pesquisa. Desta maneira, esse subsistema foi classificado de acordo com três parâmetros: ensino (transmissão), pesquisa (produção) e extensão (compartilhamento).

As camadas fragilidade, ausência, possibilidade e invisibilidade são resultado da análise dos três subsistemas e estratégia de entendimento do que possuem em comum, auxiliando no aprofundamento dos pontos de vista de suas conexões. Por exemplo, a fragilidade nas relações entre os designers no mercado, a ausência de interlocução entre os cursos de design, a possibilidade de interações amistosas e de troca que podem se estabelecer entre mercado e ensino, a Invisibilidade do design na sociedade, dada a incompreensão do que é e qual é o alcance de sua produção.

\section{Indicadores do projeto}

A etapa seguinte, representada ao fim do infográfico da figura 8 , transforma os indicadores do sistema específico deste grupo em parâmetros e requisitos de projeto: impactar de maneira dinâmica e participativa os subsistemas por meio do design, ampliar o acesso e a notoriedade do design na cidade, e aplicar o design para interagir com os subsistemas. 
Silva, A. L. S. V., Viana, A. P. Q., Nascimento, B. R., Santos, M. S., Marciano, A. B. T. \& Pereira, A. N. / Metadisciplina aplicada em Projeto de Produto, a formação de um coletivo de Design.

Figura 8: Resumo do processo que define os requisitos do metaprojeto baseado no sistema de design. Fonte: Grupo de formação do coletivo.

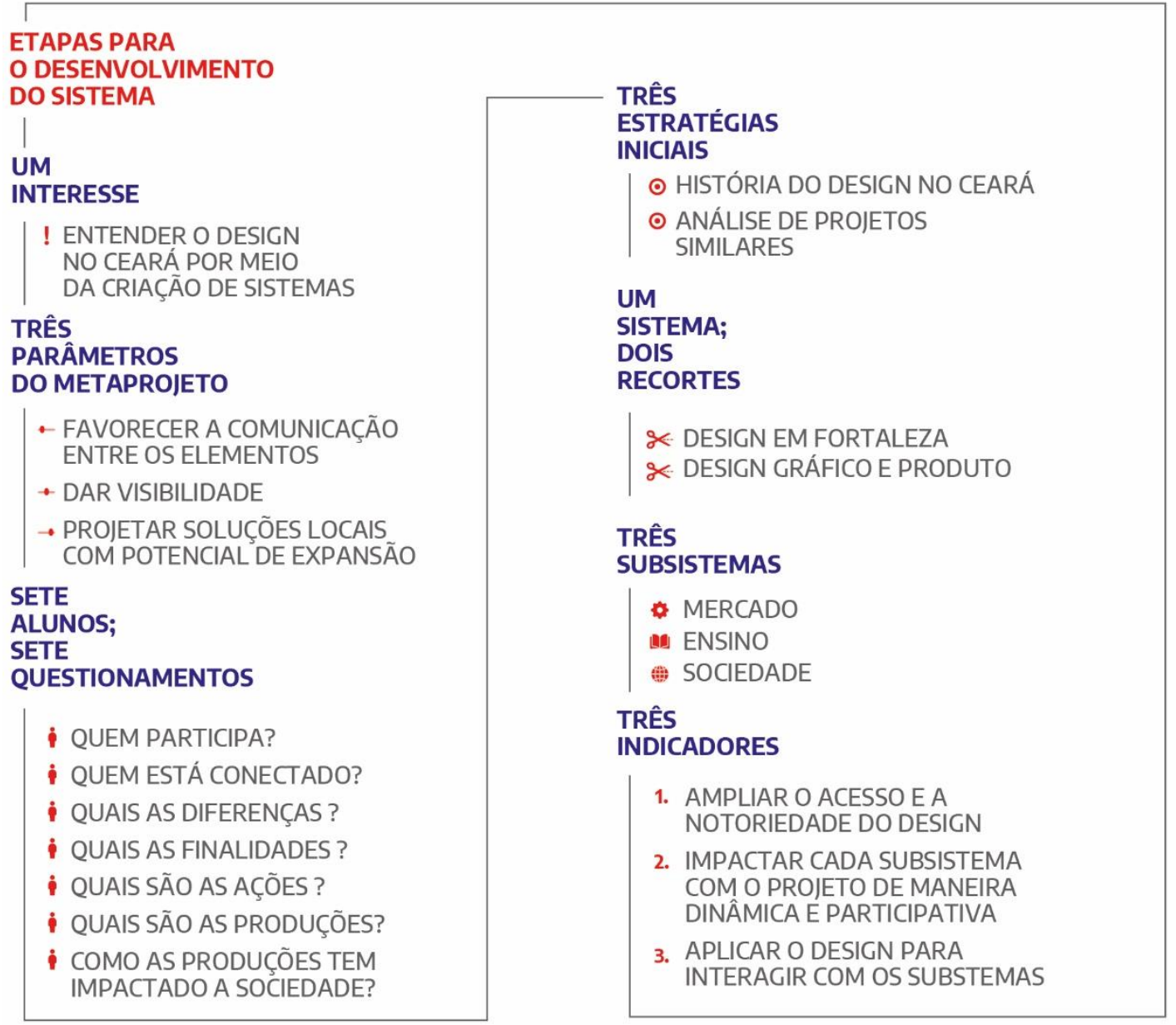

\section{Projeto}

A constatação da essência do sistema e de sua realização, nos leva a analisar a possibilidade de outras organizações emergentes do sistema para atuar nele, coletivamente. Oito coletivos foram pesquisados pelos critérios: objetivos; como agem; o seu alcance; o que são; e a justificativa da sua proposição. Esse estudo norteia a continuação do projeto como um movimento catalisador que realiza conexões por meio do design para o design.

\section{Definição de coletivo}

Paim (2009, p. 11) define coletivos como agrupamentos de indivíduos que sob um mesmo nome, atuam de forma conjunta, criativa, autoconsciente e não hierárquica para dar visibilidade a projetos e proposições cocriativas. Nestes fenômenos associativos ocorre a reunião de esforços para inventar outros percursos, táticas e espaços para si próprios. A autora relata que os coletivos costumam inventar espaços próprios chamado de "espaços cotidianos", pois atuam fora dos espaços convencionais (Paim, 2009, p. 24). Como consequência criam-se outros espaços, outras formas de agir, e novas formas de fazer, de modo a revelar uma apropriação desses espaços como resposta e solução de problemas.

A proposta do projeto revela-se na formação de um coletivo de estudantes de Design, que emerge, na disciplina de PP4, do desejo do grupo em aprimorar o sistema do design local e possibilitar o diálogo do design com outras áreas de atuação. Com base nas análises de 
Silva, A. L. S. V., Viana, A. P. Q., Nascimento, B. R., Santos, M. S., Marciano, A. B. T. \& Pereira, A. N. / Metadisciplina aplicada em Projeto de Produto, a formação de um coletivo de Design.

similares, foram priorizadas ações abstratas que provocassem discussões e que através delas fosse possível se chegar a novos entendimentos de como os elementos do sistema interagem.

\section{Definição de plataforma}

Uma plataforma pode ser considerada como interface cognitiva e social, para o desenvolvimento das relações entre os elementos reconhecidos e entre os processos colaborativos de aprendizagem (Jenkins, 2006, p. 38). A natureza da plataforma é conectar e compartilhar, os participantes podem se unir, por conta dos seus atributos que geram afinidade, e se desvincular caso preciso. A lógica conexionista é aberta a atividades que não visam apenas a lógica industrial, doméstica e de mercado, mas a abrangência da inovação, opinião e comunidade. No ato de projetar plataformas o importante é prover conexões e oportunidades de atividades, propostas tanto pela própria plataforma, como pelos demais participantes (Sakuda, 2018).

\section{Resultados}

O grupo propõe uma plataforma física e interativa que se insere em um ponto estratégico da cidade, o Departamento de Arquitetura, Urbanismo e Design da Universidade Federal do Ceará. É colocado como um marco visual a ser transcorrido em uma narrativa visual e espacial sobre design. O protótipo tridimensional projetado foi construído em escala real em estrutura de PVC e nylon, a modularidade foi proposta para facilitar a montagem/desmontagem, o manuseio e proporcionar permeabilidade. O caminho semântico circular sinaliza as quatro etapas a serem percorridas. (Figura 9).

Figura 9: Infográfico referente ao fluxo na plataforma tridimensional. Fonte: Grupo de formação do coletivo.

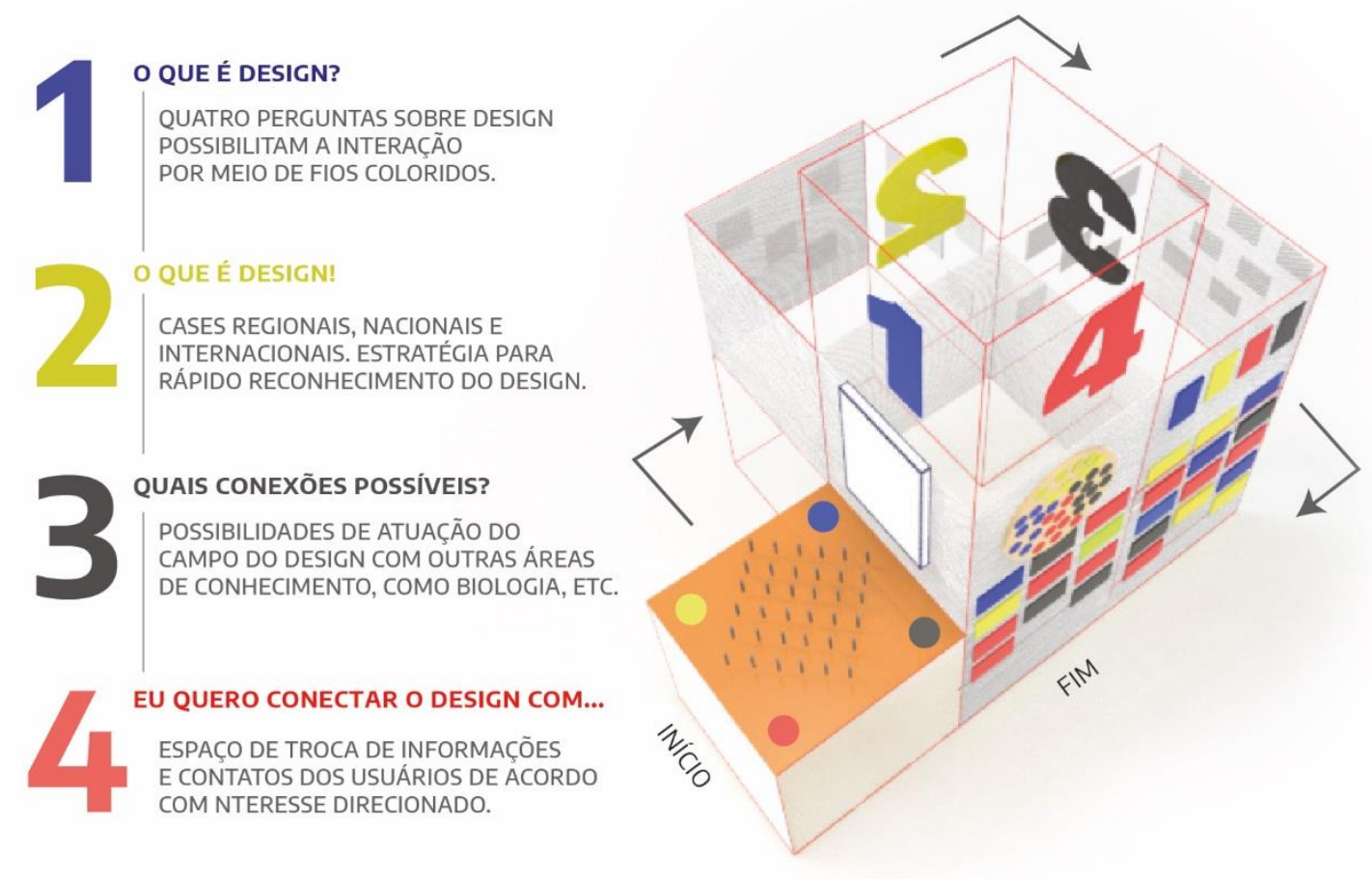

\section{O que é design?}

A primeira etapa do percurso na plataforma foi pensada para incentivar a reflexão e compartilhar concepções sobre Design. Para isso, foram elencadas quatro perguntas sobre o significado do Design: o que é? o que faz? o que precisa ter? a quem interessa? Deveriam ser respondidas ligando com linhas coloridas os diversos termos em um plano vertical. A escolha em se trabalhar com as linhas foi pensada devido a visibilidade do seu uso associada aos 
Silva, A. L. S. V., Viana, A. P. Q., Nascimento, B. R., Santos, M. S., Marciano, A. B. T. \& Pereira, A. N. / Metadisciplina aplicada em Projeto de Produto, a formação de um coletivo de Design.

termos encontrados na estrutura e as suas cores atrativas, que promoviam um maior destaque a composição. As respostas poderiam interagir, em um processo aberto.

Figura 10: Imagens da primeira etapa. Fonte: Adson Pinheiro.

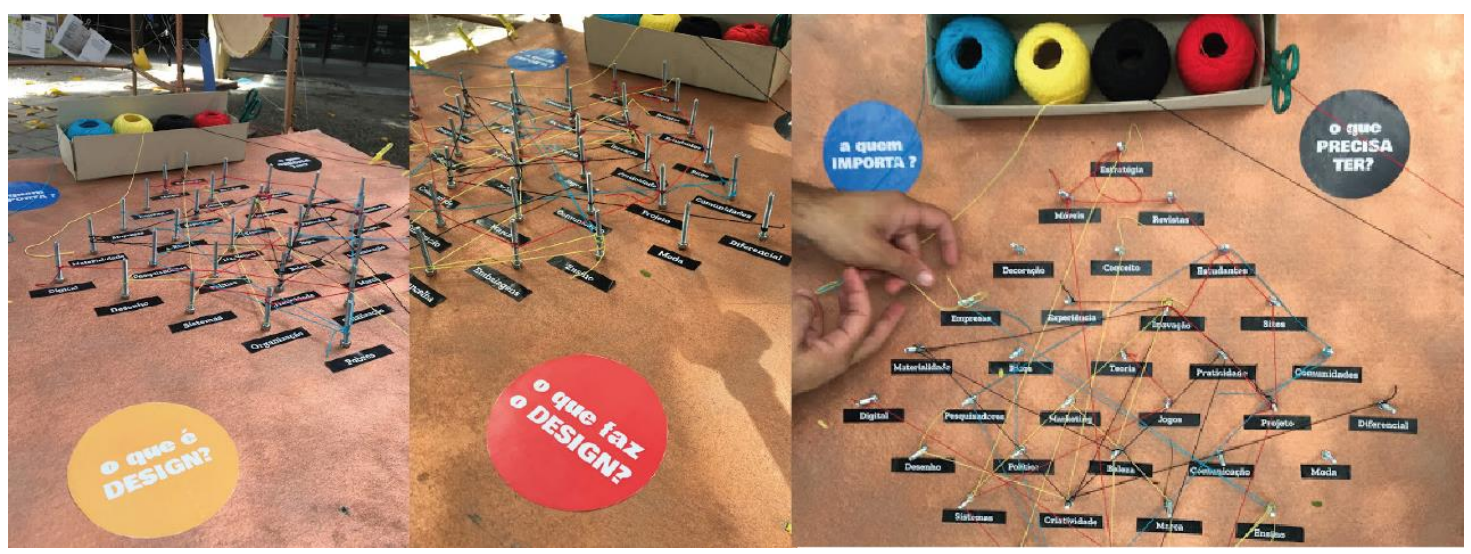

\section{O que é design!}

$\mathrm{Na}$ segunda etapa, os participantes foram incentivados a conhecer diversas referências locais, nacionais e internacionais, a fim de fornecer informações que ampliassem as discussões em torno das concepções sobre Design. Os cases expostos foram projetados em papéis em formato de sanfona que deveriam ser abertos pelos usuários.

Figura 11: Imagens da segunda etapa da ação. Fonte: Adson Pinheiro.

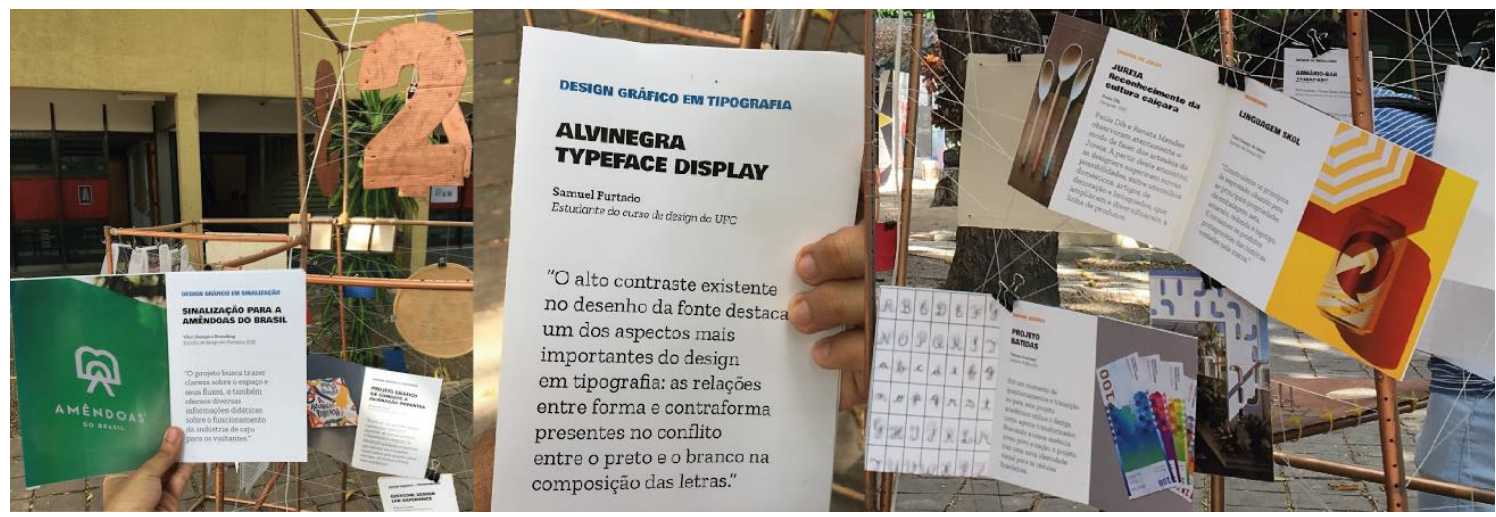

\section{Quais conexões possíveis?}

Em seguida, papéis translúcidos precisaram ser abertos para o entendimento das possíveis ligações existentes do design com outras áreas do conhecimento. Assim, foram selecionados alguns projetos que relacionavam design com áreas como: matemática, biologia, engenharia, psicologia, entre outras. 
Silva, A. L. S. V., Viana, A. P. Q., Nascimento, B. R., Santos, M. S., Marciano, A. B. T. \& Pereira, A. N. / Metadisciplina aplicada em Projeto de Produto, a formação de um coletivo de Design.

Figura 12: Imagens da terceira etapa da ação. Fonte: Adson Pinheiro.

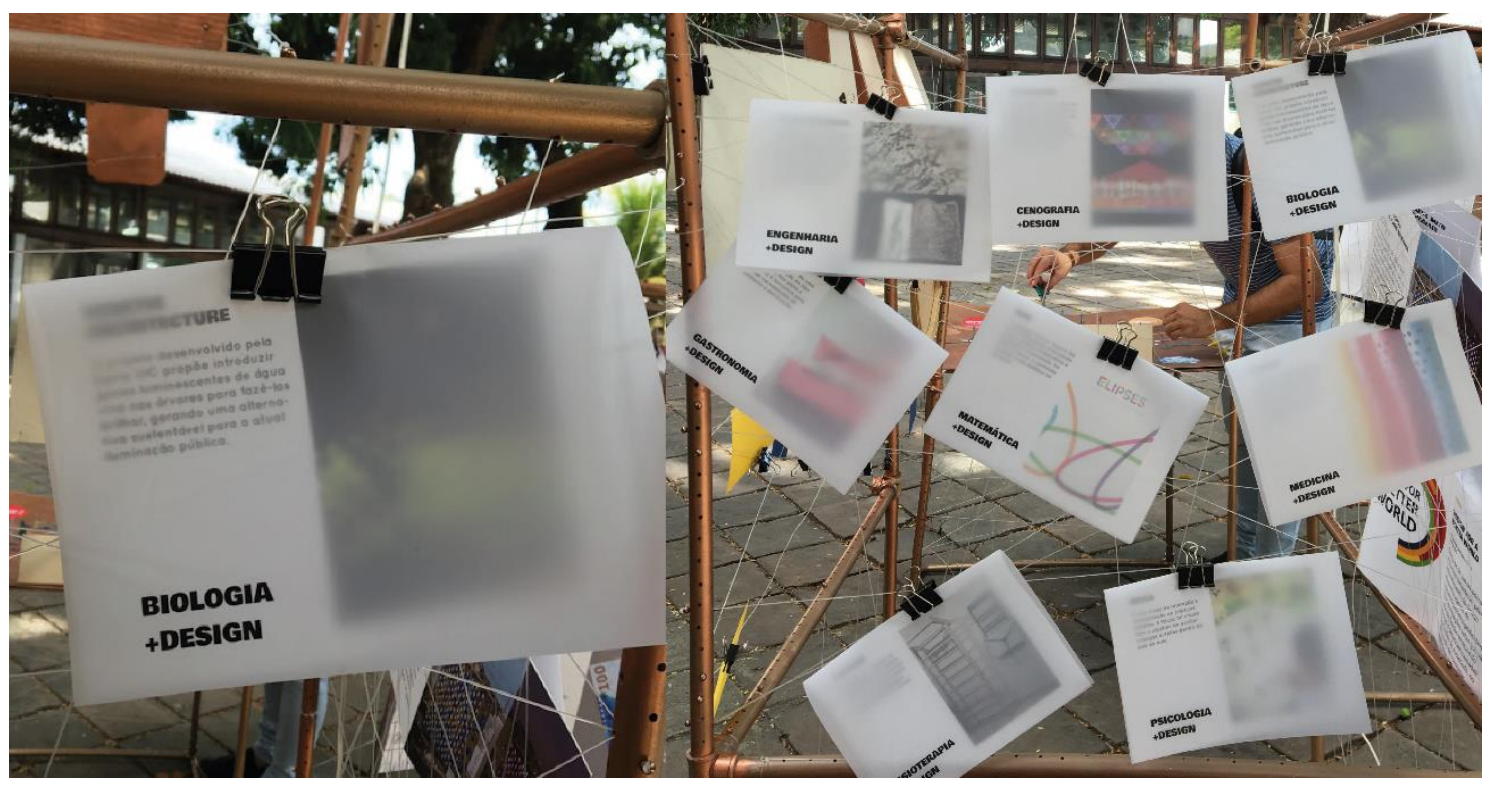

\section{Eu quero ligar o Design com...}

$\mathrm{Na}$ quarta etapa, foi criado uma malha para interação escrita em papéis com cores que significavam: "design e ensino", "design e ambiente", "design e cidade" e "design e política". Por fim, bottons foram disponibilizados aos participantes com os mesmos significados de cores, como uma forma de incentivo a formação de novos coletivos para transformar a cidade por meio do design.

Figura 13: Imagens da quarta etapa da ação. Fonte: Adson Pinheiro.

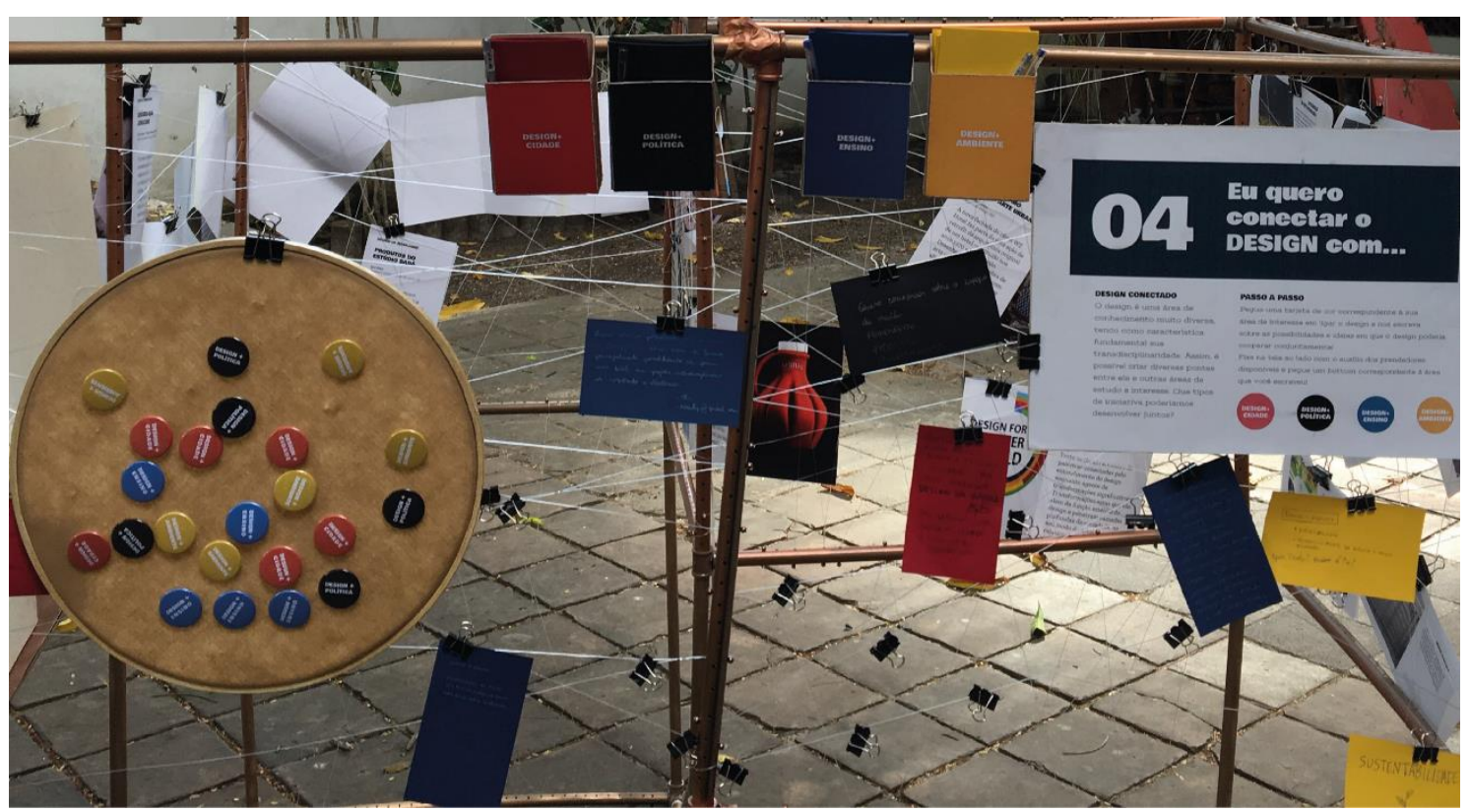


Silva, A. L. S. V., Viana, A. P. Q., Nascimento, B. R., Santos, M. S., Marciano, A. B. T. \& Pereira, A. N. / Metadisciplina aplicada em Projeto de Produto, a formação de um coletivo de Design.

\section{Conclusão}

A natureza da complexidade sistêmica da proposição da abordagem da Metadisciplina em PP4 demandou uma maneira fluida e diversa de projetar. O campo de possibilidades aberto a iniciativas criadoras e criativas, solicitou da turma emancipação, por meio de soluções projetuais comprometidas com a realidade local.

Este grupo, especialmente, assumiu deliberadamente o propósito de ser responsável por sua própria formação, encarou o desafio e os perigos de um tema tão abrangente, dentro do qual se reconheceu, se identificou e se posicionou.

No processo, cada aula foi uma etapa de transformação, não apenas no sentido de evolução do projeto, mas na partilha de descobertas, num nível subjetivo, mas também e principalmente no coletivo.

Juntos no querer, na pesquisa, na partilha, nos acordos, na catálise das relações, nos erros, consertos, nas decisões. Juntos aprenderam que ao qualificar as conexões, todo sistema se beneficia. Ensinaram que de dentro pra fora, de baixo pra cima, com autorreflexão e de mãos dadas, pode funcionar.

No projeto-coletivo o pensamento sobre o design no ensino, no mercado e na cidade de Fortaleza se revelou um metadesign: projeta o contexto onde quer operar, integra o movimento e os processos que planeja transformar e se insere como uma conexão entre os subsistemas que identificou, um processo diferente, um projeto sem soluções prontas, sem tempo de conclusão. A conclusão na verdade é um início.

\section{Referências}

Baer, K. (2009). Information Design Workbook: graphics, approaches, solutions, and inspiration +30 case studies. Beverly: Rockport Publishers.

Bonsiepe, G. (2011). Design, cultura e sociedade. São Paulo: Blucher

Brasil. (2014). Diagnóstico do Design Brasileiro. Brasília. MDIC - Ministério de Desenvolvimento, Indústria e Comércio Exterior.

Cardoso, R. (2012). Design para um mundo complexo. São Paulo: Cosac Naify.

Hooks, B. (2017). Ensinando a transgredir: a educação como prática da liberdade. Trad. de Marcelo Brandão Cipolla. São Paulo, SP: WMF Martins Fontes.

Jenkins, H. (2006). Cultura da Convergência. 2. ed. São Paulo: Aleph.

Lynch, K. (1960). The image of the city. Cambridge: The M.I.T. Press.

Moraes, D. (2010). Metaprojeto: o design do design. São Paulo: Blucher.

Paim, C. (2009). Coletivos e iniciativas coletivas: modos de fazer na America Latina contemporânea. Tese (Doutorado) - UFRGS. Porto Alegre.

Pereira, A. N. (2017). Levantamento dos Principais Escritórios de Design Gráfico e Produto da Região Metropolitana de Fortaleza. Em Encontros Universitários da UFC, Fortaleza, v. 2, p. 4405.

Sakuda, L. O. (2018). Plataformas digitais e o novo espírito do capitalismo: Estudo sobre a indústria de jogos digitais. Em Programa Observatório Itaú Cultural de Pesquisa em Economia da Cultura - 2017. (Ed.) São Paulo: Itaú Cultural.

Silva, A. L. S. V. et.al. (2019). Metadisciplina na inter-relação entre o design e a educação. In: Andrade, D. (Ed.). Educação no século XXI: Artes \& Design. Belo Horizonte: Poisson. p. $175-187$. 
Silva, A. L. S. V., Viana, A. P. Q., Nascimento, B. R., Santos, M. S., Marciano, A. B. T. \& Pereira, A. N. / Metadisciplina aplicada em Projeto de Produto, a formação de um coletivo de Design.

Vassão, C. A. (2010). Metadesign: ferramentas, estratégias e ética para a complexidade. São Paulo: Blucher, 2010.

Vieira, J. A. (2008). Ontologia Sistêmica e Complexidade. Formas de conhecimento e arte: arte e ciência uma visão a partir da complexidade. Fortaleza: Expressão Gráfica e Editora.

\section{Sobre o(a/s) autor(a/es)}

Anna Lúcia dos Santos Vieira e Silva, Doutora, UFC, Brasil <lilu@dau.ufc.br>

Adson Pinheiro Queiroz Viana, Graduando, UFC, Brasil <adson.queiroz12@gmail.com> Alessandra do Nascimento Pereira, Graduanda, UFC, Brasil <alessp@design.ufc.br> Ana Beatriz Teixeira Marciano, Graduanda, UFC, Brasil <beatrizteixeirr@gmail.com> Bruno Ribeiro do Nascimento, Graduando, UFC, Brasil <brunothiagodesign@gmail.com> Marina de Sousa Santos, Graduanda, UFC, Brasil <masousasantos1@gmail.com> 